\title{
Protein-bound polysaccharide-K reduces colitic tumors and improves survival of inflammatory bowel disease in vivo
}

\author{
NORIFUMI TSUTSUMI ${ }^{1}$, SHUNJI KOHNOE ${ }^{1,2}$, HIDETO SONODA $^{1,2}$, ATSUSHI GUNTANI $^{1}$, \\ TATSUYA RIKIMARU ${ }^{1}$, KEN-ICHI TAGUCHI ${ }^{3}$, MORIMASA TOMIKAWA ${ }^{1}$, \\ YOSHIHIRO KAKEJI ${ }^{1}$, HIDEAKI NAKASHIMA ${ }^{1}$ and YOSHIHIKO MAEHARA ${ }^{1}$ \\ ${ }^{1}$ Department of Surgery and Science, Graduate School of Medical Sciences, Kyushu University, Fukuoka 812-8582; \\ ${ }^{2}$ Department of General Surgery, Fukuoka Dental College Medical and Dental Hospital, Fukuoka 814-0193; \\ ${ }^{3}$ Department of Pathology, National Kyushu Cancer Center, National Hospital Organization, Fukuoka 811-1395, Japan
}

Received January 27, 2011; Accepted June 10, 2011

DOI: 10.3892/ol.2011.336

\begin{abstract}
Protein-bound polysaccharide-K (PSK) is a biological response modifier that possesses antitumor effects against various tumors. Although an inflammatory response has been considered to play an important role in the development of colorectal cancer, the anti-inflammatory effect of PSK has yet to be elucidated. An inflammatory bowel disease (IBD)induced colorectal tumor model with 1.2-dimethyl hydrazine (DMH) and dextran sodium sulfate (DSS) was used to examine the effects of PSK on tumor suppression and survival. Although $90 \%$ of the mice that were not treated with PSK developed colitic tumors, oral administration of PSK suppressed tumor formation by less than 30\%. Although deaths associated with DSS-induced melena were observed, PSK significantly reduced mortality. In conclusion, the present study showed that PSK not only suppressed colorectal tumor formation in the DMH+DSS-induced IBD model, but also improved the survival rate, indicating that anti-inflammatory activity is one of the mechanisms for the antitumor effects of PSK.
\end{abstract}

\section{Introduction}

In recent years, the incidence of colorectal cancer has ranked high among that of malignant tumors (1). Various factors, including genetic abnormalities (2) and angiogenesis (3), are associated with the development and growth of colorectal cancer. Among these factors, the inflammatory response has recently been indicated by findings that anti-inflammatory agents including aspirin reduce the risk of colorectal cancer

Correspondence to: Dr Shunji Kohnoe, Department of Surgery and Science, Graduate School of Medical Sciences, Kyushu University, 3-1-1 Maidashi, Higashi-ku, Fukuoka 812-8582, Japan

E-mail: kounoe@surg2.med.kyushu-u.ac.jp

Key words: colitis-related cancer, colorectal cancer, inflammation, protein-bound polysaccharide-K
$(4,5)$, and that ulcerative colitis is a risk factor for colorectal cancer (6).

Protein-bound polysaccharide-K (PSK) is a biological response modifier that is extracted from the basidiomycete Coriolus vesicolor, (7) and is widely used in Japan and Taiwan as a postoperative adjuvant immunotherapeutic agent. PSK has exhibited anticancer effects in in vivo and in vitro experimental studies, and has suppressed cancer recurrence when used in combination with anticancer agents in clinical studies $(8,9)$. However, the anti-inflammatory effects of PSK have yet to be fully elucidated, and its effect on colorectal carcinogenesis induced by inflammatory bowel disease (IBD) remains unknown.

The dextran sodium sulfate (DSS) model is the most widely used IBD model. Oral administration of DSS, which is not a carcinogenic substance with genotoxicity, induces inflammation in the large bowel and the lesions are histologically similar to those of human ulcerative colitis $(10,11)$. Previously, 1.2-dimethylhydrazine (DMH) was used in combination with DSS to increase the tumor incidence of the IBD model (12).

The aim of the present study was to examine the effects of PSK on the development of colorectal tumor in a DMH+DSSinduced IBD mouse model.

\section{Materials and methods}

Reagents. DMH was purchased from Wako Pure Chemical Industries (Osaka, Japan). DSS with a molecular weight of 36,000-50,000 was obtained from ICN Biochemicals (Aurora, $\mathrm{OH}, \mathrm{USA})$.

Animals. Five-week-old male Crj: CD-1 mice (ICR) were purchased from KBT Oriental (Charles River Grade, Tosu, Saga, Japan). Animal experiments were performed according to approved protocols and in accordance with recommendations for the proper care and use of laboratory animals by the Committee for Animals at Fukuoka Dental College, and according to the Law (No. 105) and Notification (No. 6) of the Japanese Government. The animals were housed in plastic 


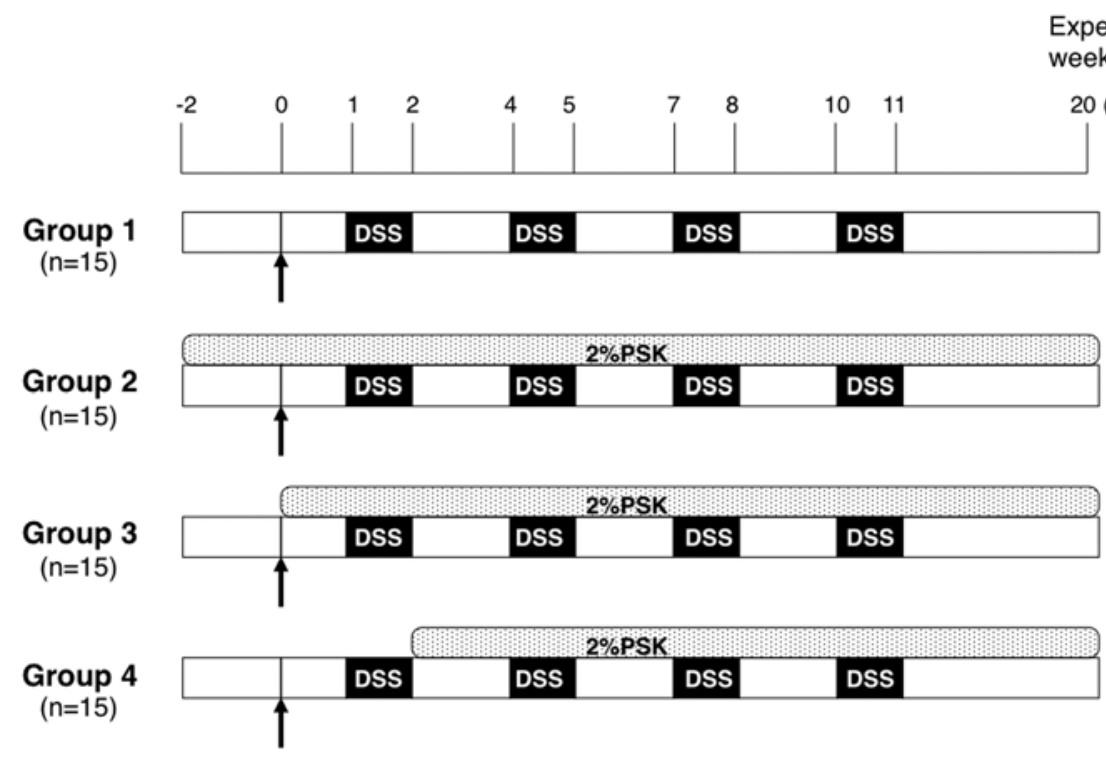

Figure 1. Experimental protocol. Arrows indicate intraperitoneal injection of $20 \mathrm{mg} / \mathrm{kg}$ DMH. Starting 1 week after the injection, animals were given $2 \%$ (w/v) DSS in drinking water for 1 week followed by 2 weeks without DSS. This treatment cycle was carried out 4 times.

cages (4 or 5 per cage) with free access to drinking water and a pelleted diet (MF pellet; Oriental Yeast, Tokyo, Japan) under controlled conditions of humidity $(50 \pm 10 \%)$, light $(12: 12 \mathrm{~h}$ light:dark cycle) and temperature $\left(23 \pm 2^{\circ} \mathrm{C}\right)$. During the experimental period, the mice were fed a basal diet of MF pellets or a PSK-containing diet of MF pellets mixed with 2\% PSK (Kureha Corporation, Tokyo, Japan).

Inflammation-related colon carcinogenesis models. A total of 63 male ICR mice were divided into 5 groups as follows (Fig. 1): Group $1(\mathrm{n}=15)$, model mice not treated with PSK; Group $2(n=15)$, model mice pretreated with PSK from 2 weeks prior to DMH injection; Group 3 ( $n=15)$, model mice treated with PSK at the same time as DMH injection; Group $4(n=15)$, model mice treated with PSK from 2 weeks after DMH injection; and Group $5(\mathrm{n}=3)$, normal control group without intervention. DMH was dissolved in $0.9 \%$ saline and the $\mathrm{pH}$ was adjusted to 6.5 . Groups 1-4 were given a single intraperitoneal injection of $20 \mathrm{mg} / \mathrm{kg}$ DMH. Starting 1 week after the injection, the animals were given $2 \%(\mathrm{w} / \mathrm{v})$ DSS in drinking water for 1 week followed by 2 weeks without DSS . This treatment cycle was repeated 4 times. Group 5 (normal control) received no treatment. The animals were observed daily for clinical signs and death. At week 20, any surviving animals were sacrificed with an overdose of ether.

Tumor formation and light microscopic examination. The liver, kidneys and spleen were removed and weighed. The large bowels were resected, cut open longitudinally and filled with $10 \%$ buffered formalin. The number of tumors were counted. Formalin-fixed colonic tissues were routinely processed for histological examination. Histological diagnosis was performed on $\mathrm{H} \& \mathrm{E}$-stained sections.

Immunohistochemistry. The sections were deparaffinized and incubated with $3 \%$ non-fat milk for $30 \mathrm{~min}$ to minimize the non-specific binding of the primary antibody. The sections were then incubated with the primary anti- $\beta$-catenin antibody (H-102; Santa Cruz Biotechnology, Santa Cruz, CA, USA) overnight at $4{ }^{\circ} \mathrm{C}$ in a moisture chamber. All of the following steps were separated by 3 washes with PBS for $5 \mathrm{~min}$. To inhibit any endogenous peroxidase activity, the sections were incubated with $0.3 \%(\mathrm{w} / \mathrm{v}) \mathrm{H}_{2} \mathrm{O}_{2}$ in absolute methanol for $30 \mathrm{~min}$. The sections were then incubated with peroxidase-labeled antibody (Dako EnVision System; Hamburg, Germany) for $30 \mathrm{~min}$ at room temperature. Visualization of a positive reaction was developed with a peroxidase substrate solution that contained $0.02 \%(\mathrm{w} / \mathrm{v}) \mathrm{H}_{2} \mathrm{O}_{2}$ and $0.1 \%(\mathrm{w} / \mathrm{v})$ 3,3'-diaminobenzidine tetrahydrochloride (Merck, Darmstadt, Germany) in PBS, to give the reaction product a brown color, and then the sections were counterstained with hematoxylin. Non-immune rabbit IgG was used instead of the primary antibody as a negative control.

Statistical analysis. Data were expressed as the mean \pm SD, and analyzed by one-way ANOVA with Fisher's adjustment and the Student's t-test. For the survival analysis, survival curves were constructed using the Kaplan-Meier method, and the level of significance of differences between curves was determined using the log-rank test. $\mathrm{P}<0.05$ was considered to be statistically significant.

\section{Results}

Changes in body weight. At the start of the experiment, mice were divided into groups that had a similar body weight distribution, with a mean of $\sim 30 \mathrm{~g}$. The bodyweights (mean $\pm \mathrm{SD}$ ) at necropsy 20 weeks after DMH injection were $51.25 \pm 6.41 \mathrm{~g}$ in Group 1,51.33 $\pm 5.15 \mathrm{~g}$ in Group 2, 57.46 $\pm 4.69 \mathrm{~g}$ in Group 3 and $50.01 \pm 5.50 \mathrm{~g}$ in Group 4. Compared to Group 1, no significant difference was found in Group 2 ( $\mathrm{P}=0.9739$, t-test) and Group $4(\mathrm{P}=0.6175)$. However, a significant increase $(\mathrm{P}=0.0118)$ was observed in Group 3, in which PSK was started at the same time as DMH injection. 


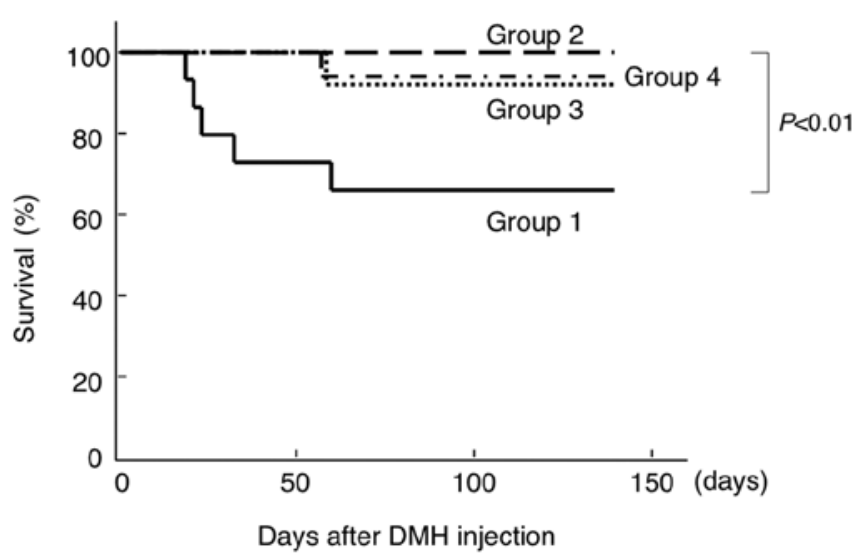

Figure 2. Effect of PSK administration on survival after DMH injection followed by DSS administration in CD-1 mice. PSK improved the survival rate significantly, irrespective of the time of administration. The data were analyzed using the log-rank test.

PSK improved survival rate in IBD model. After DSS administration was started, death accompanied by melena was observed in the non-PSK-treated group (Group 1), and 5 of 15 mice $(33.3 \%)$ died during the experimental period of 9 weeks (Fig. 2). However, the survival rates were significantly improved in the PSK-treated groups (groups 2-4) compared to the non-PSK-treated group, irrespective of the time of PSK initiation. The weights of the organs, including the liver, were measured at the end of the experimental period in all groups, and no significant differences were observed between the groups (data not shown).

PSK suppressed development of colorectal tumor in IBD model irrespective of $\beta$-catenin expression. The antineoplastic effect of PSK was investigated in a mouse model of colon carcinogenesis whereby administration of $\mathrm{DMH}$ followed by repeated DSS ingestion caused colonic inflammation and the subsequent development of multiple colonic tumors. Of 10 surviving mice in the non-PSK group, 9 (90\%) had macroscopic colorectal tumors. These lesions were observed from the middle to distal portion of the large intestine, and no tumor was found in the small intestine. The colorectal tumors were confirmed histopathologically to be well- to moder- ately differentiated tubular adenocarcinomas (Fig. 3). PSK administration suppressed tumor formation to an incidence of approximately one-third [tumors found in 2 of 15 mice $(27 \%)$ in Group 2 and 4 of 14 mice (29\%) in Group 3]. This effect was reduced when PSK administration was started 2 weeks after DMH injection [tumors found in 7 of 14 mice $(50 \%)$ in Group 4] (Table I).

To elucidate the mechanism of the antitumor effect of PSK, we examined the in vivo expression of $\beta$-catenin with or without PSK. Tumor specimens, including those in the PSK and non-PSK groups, showed a $\beta$-catenin-positive reaction. $\beta$-catenin was abundantly expressed in the cytoplasm or nucleus in the majority of tumors, but not in interstitial cells (Fig. 4). The antitumor effect of PSK was not likely to have been an effect of the expression of $\beta$-catenin in colonic adenocarcinoma in the IBD model.

\section{Discussion}

To the best of our knowledge, this was the first study to reveal that PSK suppressed the development of colorectal tumors and improved survival in a mouse model of IBD.

Although DSS is commonly used to create an IBD-induced colorectal cancer model, the tumor incidence is low $(13,14)$. It is not possible to increase the DSS dose to increase tumor incidence as the inflammatory response would intensify and lead to higher mortality associated with melena. Kohno et al (12) have reported that tumor incidence is increased when an intraperitoneal injection of DMH is used in combination with DSS administration. A high dose of DMH may result in death due to hepatotoxicity. Subsequently, a DMH dose of $20 \mathrm{mg} /$ $\mathrm{kg}$ was used, followed by $2 \%$ DSS given in drinking water. DSS (2\%) was administered in 4 cycles, each consisting of 1 week of treatment followed by 2 weeks without treatment. The survival rate of mice in our model was lower than that in previous studies, probably due to the larger DSS dose used and a longer administration period.

Harada et al (15) have reported that administration of PSK alone suppressed the growth of transplanted colorectal cancer in vivo. Following transplantation of colon-26 carcinoma cells into the intestinal tract of Balb/c mice and the treatment of mice with PSK or placebo, these authors observed that tumor growth was significantly suppressed in the PSK-treated group.

Table I. Effect of PSK treatment on the incidence of colon tumors in mice treated with DMH and DSS.

Group no.

(No. of mice examined)
Treatment arm

(No. of mice surviving)
No. of mice with colon tumors (\%) (Multiplicity)

\begin{tabular}{lll}
\hline $1(15)$ & PSK $(-)(10)$ & $9(90 \%)$ \\
$2(15)$ & PSK $(+; 2$ weeks prior to DMH) $(15)$ & $(1.00 \pm 0.47)$ \\
& & $(27 \%)^{\mathrm{a}}$ \\
$3(15)$ & PSK $(+;$ same time as DMH) $(14)$ & $4(29 \%)^{\mathrm{a}}$ \\
& & $(0.43 \pm 0.85)$ \\
$4(15)$ & PSK $(+; 2$ weeks after DMH) $(14)$ & $7(50 \%)$ \\
& & $(0.57 \pm 0.65)$
\end{tabular}



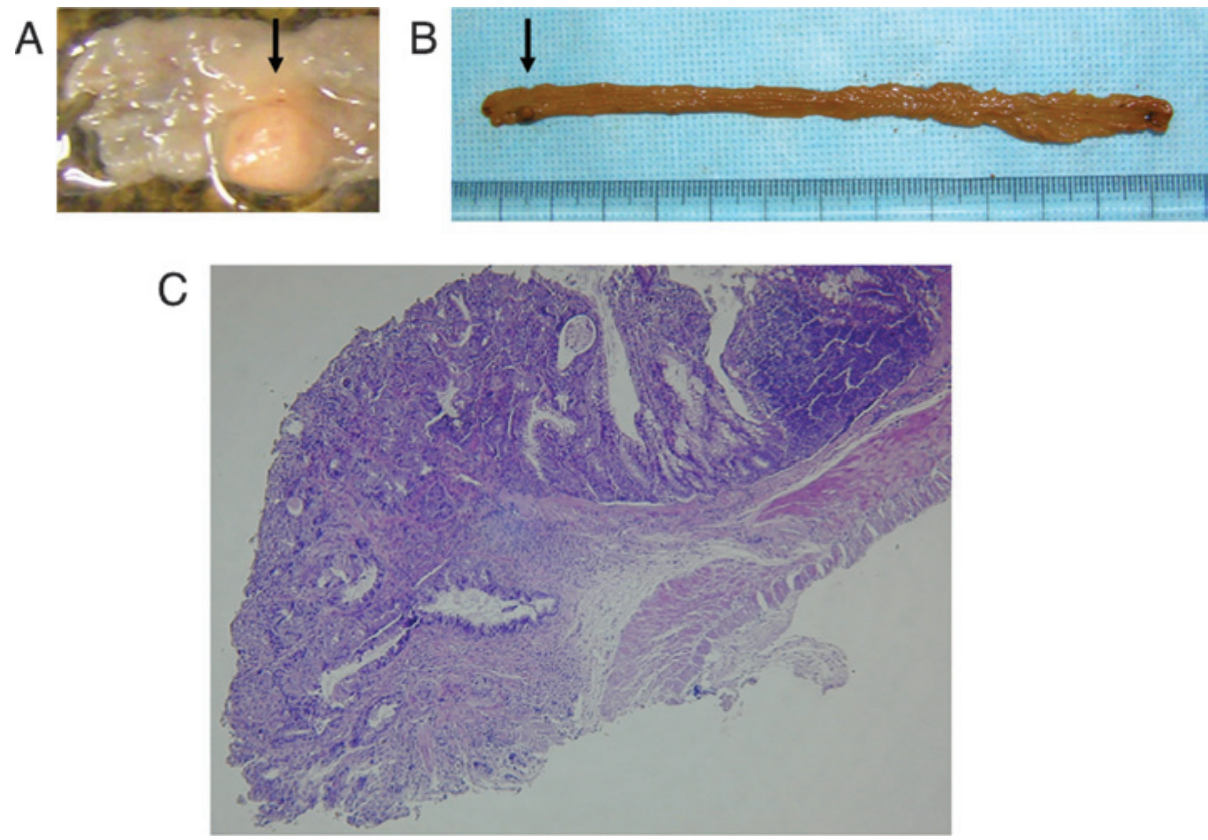

Figure 3. A colonic lesion developed in mice treated with DMH and DSS. (A and B) A macroscopic view of the large bowel. (A) The arrow indicates colonic tumor prior to fixation by formalin. (B) The arrow indicates formalin-fixed colonic tumor. (C) A light micrograph of the colonic lesion. H\&E-stained section shows tubular adenocarcinoma invading the submucosa. Original magnification, x20.
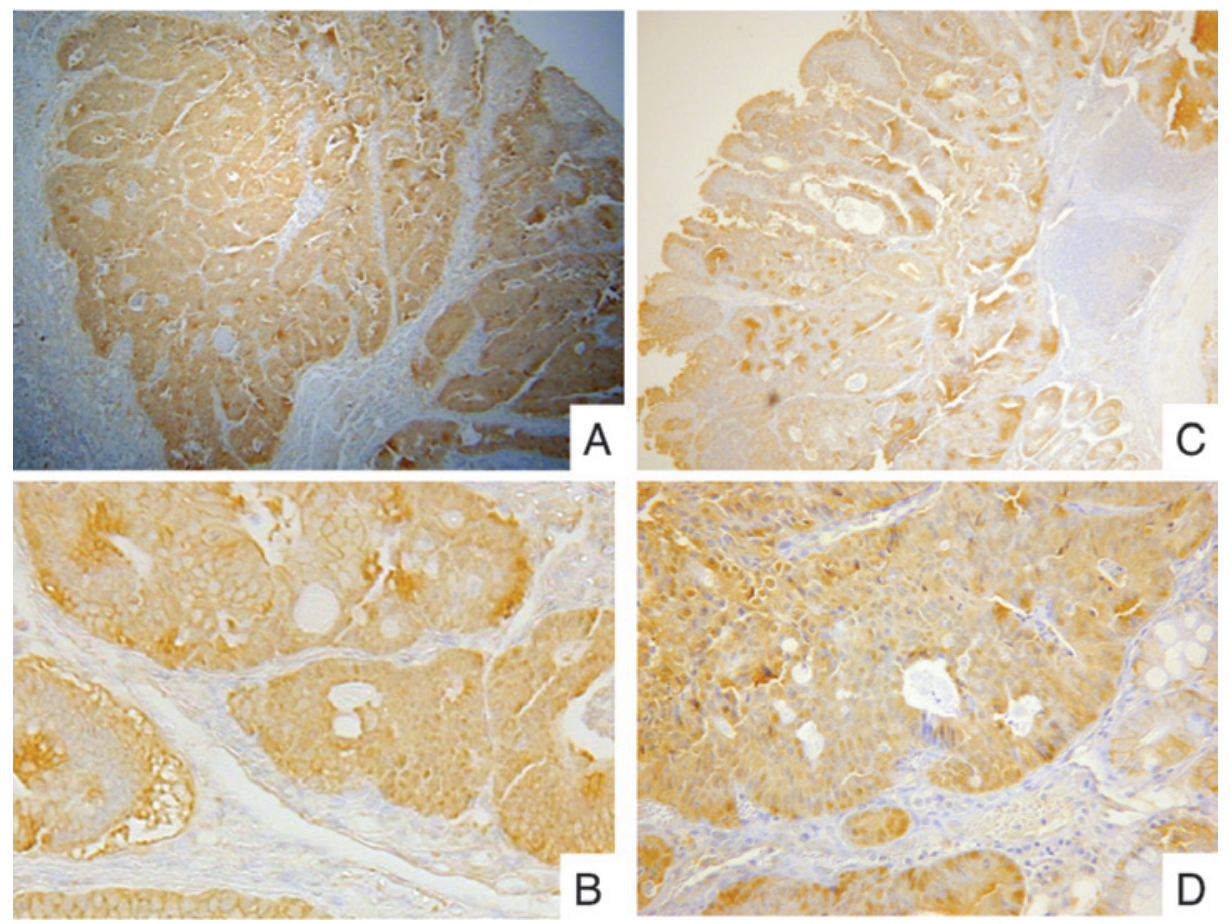

Figure 4. Immunohistochemistry of $\beta$-catenin in colonic adenocarcinoma in mice treated with DMH and DSS. $\beta$-catenin was abundantly expressed in the cytoplasm or nucleus in the majority of the tumors but not in the interstitial cells, regardless of the administration of PSK. (A and B) Group 1, model mice not treated with PSK. (C and D) Group 2, model mice pretreated with PSK from 2 weeks prior to DMH injection. Original magnification, x40 and x200, respectively.

In the present study, as expected, PSK suppressed tumor development in the IBD model. This suppressive effect was dependent on the time period of PSK administration, and the effect was reduced when PSK was started later than DMH exposure. Our findings indicate that the antitumor effect of PSK exerted prior to or shortly after DSS exposure was important in preventing tumorigenesis.

$\beta$-catenin is a multifunctional molecule that is involved in cadherin-mediated cell-cell adhesion. Normally, $\beta$-catenin is localized in cell-cell junctions with extremely low levels in the 
cytoplasm or nucleus. The accumulation of $\beta$-catenin in the cytoplasm or nucleus as a consequence of mutant $\beta$-catenin is associated with colon carcinogenesis (16). In the present study, $\beta$-catenin was strongly expressed in the cytoplasm and nucleus of adenocarcinoma cells regardless of the administration of PSK.

The carcinoma cells in the IBD model would have undergone the same carcinogenic process as ordinary sporadic carcinomas. In other words, PSK may not have changed any carcinogenic mutation process, but may have suppressed tumor growth and slowed its rate, which was promoted by the chronic inflammatory response with DSS.

p16 expression was examined by immunohistochemistry, and it was observed that it was not expressed in the tumor cells of the PSK administration groups or the non-PSK group (data not shown). Various studies have revealed the downregulation of p16 expression in sporadic colorectal cancers as well as colitic cancers (17).

Another finding was that PSK improved the survival rate of the IBD model mice, irrespective of the time of admini stration. The cause of death due to DMH is hepatotoxicity, which appears 2-3 days after DMH administration (12). In our study, death occurred in the mice after DSS administration was started (from day 10 following DMH injection), and the cause of death was associated with melena and diarrhea. We assume that the deaths were caused by inflammatory intestinal damage induced by DSS. These findings indicate that PSK suppressed the inflammatory intestinal damage induced by DSS.

The effect of PSK on inflammatory responses has not been studied in detail. PSK has been reported to induce cytokine production, and to be associated with the expression of cytokines, including interleukin (IL)-1, 2, 4, 6, 8 and 10, tumor necrosis factor (TNF)- $\alpha$, and transforming growth factor- $\beta$ (18-21). However, the significance of these findings in vivo has yet to be clarified. PSK has been reported to prolong survival in cecal ligation and puncture-induced sepsis, (22) indicating that PSK has anti-inflammatory or antibacterial effects.

The relationship between tumorigenesis and inflammation is an area of study that has attracted recent attention (23). COX-2 inhibitors have been shown to prevent colorectal polyps $(24,25)$. It has been reported that mesalamine, the drug of choice in the maintenance of remission and treatment of IBD, is capable of reducing the incidence of IBD-related colorectal cancer (26). Various factors are involved, including TNF- $\alpha$, interferon- $\gamma$, IL-6, suppressor of cytokine signaling (SOCS) (27) and nuclear factor- $\kappa \mathrm{B}(28,29)$. Disruption of the balance between these cytokines is thought to aggravate the inflammatory response. The SOCS-1 gene functions as a cancer suppressor gene that has the unique action of suppressing carcinogenesis by negatively regulating inflammation (30). This study did not identify the factor that is involved in the effect of PSK. Further studies are required to elucidate the molecular mechanisms of the action of PSK.

In conclusion, using a DSS-induced IBD model, PSK not only suppressed the development of colorectal tumors, but also improved the survival rate of the IBD model. These findings indicate that the anti-inflammatory action is one of the mechanisms for the antitumor effects of PSK.

\section{Acknowledgements}

This study was supported in part by Grants-in-Aid from the Japanese Ministry of Education, Culture, Sports, Science and Technology. Materials for this study were partially funded by a grant from Kureha Corporation (Japan), which manufactures PSK.

\section{References}

1. Parkin DM: Global cancer statistics in the year 2000. Lancet Oncol 2: 533-543, 2001.

2. Sjoblom T, Jones S, Wood LD, Parsons DW, Lin J, Barber TD, Mandelker D, Leary RJ, Ptak J, Silliman N, Szabo S, Buckhaults P, Farrell C, Meeh P, Markowitz SD, Willis J, Dawson D, Willson JK, Gazdar AF, Hartigan J, Wu L, Liu C, Parmigiani G, Park BH, Bachman KE, Papadopoulos N, Vogelstein B, Kinzler KW and Velculescu VE: The consensus coding sequences of human breast and colorectal cancers. Science 314: 268-274, 2006.

3. Tsutsumi N, Yonemitsu Y, Shikada Y, Onimaru M, Tanii M, Okano S, Kaneko K, Hasegawa M, Hashizume M, Maehara Y and Sueishi K: Essential role of PDGFRalpha-p70S6K signaling in mesenchymal cells during therapeutic and tumor angiogenesis in vivo: role of PDGFRalpha during angiogenesis. Circ Res 94: 1186-1194, 2004

4. Flossmann E and Rothwell PM: British Doctors Aspirin Trial and the UK-TIA Aspirin Trial. Effect of aspirin on long-term risk of colorectal cancer: consistent evidence from randomised and observational studies. Lancet 369: 1603-1613, 2007.

5. Chan AT, Ogino S and Fuchs CS: Aspirin and the risk of colorectal cancer in relation to the expression of COX-2. N Engl J Med 356: 2131-2142, 2007.

6. Rutter M, Saunders B, Wilkinson K, Rumbles S, Schofield G, Kamm M, Williams C, Price A, Talbot I and Forbes A: Severity of inflammation is a risk factor for colorectal neoplasia in ulcerative colitis. Gastroenterology 126: 451-459, 2004.

7. Tsukagoshi S, Hashimoto Y, Fujii G, Kobayashi H, Nomoto K and Orita K: Krestin (PSK). Cancer Treat Rev 11: 131-155, 1984.

8. Fisher M and Yang LX: Anticancer effects and mechanisms of polysaccharide-K (PSK): implications of cancer immunotherapy. Anticancer Res 22: 1737-1754, 2002.

9. Ohwada S, Ikeya T, Yokomori T, Kusaba T, Roppongi T, Takahashi T, Nakamura S, Kakinuma S, Iwazaki S, Ishikawa H, Kawate S, Nakajima T and Morishita Y: Adjuvant immunochemotherapy with oral Tegafur/Uracil plus PSK in patients with stage II or III colorectal cancer: a randomised controlled study. Br J Cancer 90: 1003-1010, 2004.

10. Okayasu I, Hatakeyama S, Yamada M, Ohkusa T, Inagaki Y and Nakaya R: A novel method in the induction of reliable experimental acute and chronic ulcerative colitis in mice. Gastroenterology 98: 694-702, 1990.

11. Cooper HS, Murthy SN, Shah RS and Sedergran DJ: Clinicopathologic study of dextran sulfate sodium experimental murine colitis. Lab Invest 69: 238-249, 1993.

12. Kohno H, Suzuki R, Sugie S and Tanaka T: Beta-catenin mutations in a mouse model of inflammation-related colon carcinogenesis induced by 1.2-dimethylhydrazine and dextran sodium sulfate. Cancer Sci 96: 69-76, 2005.

13. Okayasu I, Yamada M, Mikami T, Yoshida T, Kanno J and Ohkusa T: Dysplasia and carcinoma development in a repeated dextran sulfate sodium-induced colitis model. J Gastroenterol Hepatol 17: 1078-1083, 2002

14. Takesue F, Korenaga D, Yao T, Kabashima A and Sugimachi K: Development of colonic neoplasms and expressions of p53 and p21 proteins in experimental colitis of mice induced by dextran sulfate sodium. J Exp Clin Cancer Res 20: 413-418, 2001.

15. Harada M, Matsunaga K, Oguchi Y, Iijima H, Tamada K, Abe K, Takenoyama M, Ito O, Kimura G and Nomoto K: Oral administration of PSK can improve the impaired anti-tumor $\mathrm{CD}^{+} \mathrm{T}$-cell response in gut-associated lymphoid tissue (GALT) of specificpathogen-free mice. Int J Cancer 70: 362-372, 1997.

16. Brabletz T, Jung A and Kirchner T: Beta-catenin and the morphogenesis of colorectal cancer. Virchows Arch 441: 1-11, 2002.

17. Guan RJ, Fu Y, Holt PR and Pardee AB: Association of K-ras mutations with p16 methylation in human colon cancer. Gastroenterology 116: 1063-1071, 1999. 
18. Hirose K, Zachariae CO, Oppenheim JJ and Matsushima K: Induction of gene expression and production of immunomodulating cytokines by PSK in human peripheral blood mononuclear cells. Lymphokine Res 9: 475-483, 1990.

19. Kato M, Hirose K, Hakozaki M, Ohno M, Saito Y, Izutani R, Noguchi J, Hori Y, Okumoto S, Kuroda D, et al: Induction of gene expression for immunomodulating cytokines in peripheral blood mononuclear cells in response to orally administered PSK, an immunomodulating protein-bound polysaccharide. Cancer Immunol Immunother 40: 152-156, 1995.

20. Yefenof E, Gafanovitch I, Oron E, Bar M and Klein E: Prophylactic intervention in radiation-leukemia-virus-induced murine lymphoma by the biological response modifier polysaccharide K. Cancer Immunol Immunother 41: 389-396, 1995.

21. Habelhah H, Okada F, Nakai K, Choi SK, Hamada J, Kobayashi M and Hosokawa M: Polysaccharide $\mathrm{K}$ induces $\mathrm{Mn}$ superoxide dismutase (Mn-SOD) in tumor tissues and inhibits malignant progression of QR-32 tumor cells: possible roles of interferon alpha, tumor necrosis factor alpha and transforming growth factor beta in Mn-SOD induction by polysaccharide K. Cancer Immunol Immunother 46: 338-344, 1998.

22. Ohmura Y, Matsunaga K and Suzuki T: Protective effect of a protein-bound polysaccharide, PSK, on CLP-induced sepsis in mice transplanted orthotopically with colon tumor. Shock 25: $36-42,2006$

23. Elwood PC, Gallagher AM, Duthie GG, Mur LAJ and Morgan G: Aspirin, salicylates, and cancer. Lancet 373: 1301-1309, 2009.

24. Arber N, Eagle CJ, Spicak J, Racz I, Dite P, Hajer J, Zavoral M, Lechuga MJ, Gerletti P, Tang J, Rosenstein RB, Macdonald K, Bhadra P, Fowler R, Wittes J, Zauber AG, Solomon SD and Levin B: PreSAP Trial Investigators. Celecoxib for the prevention of colorectal adenomatous polyps. N Engl J Med 355: 885-895, 2006.
25. Bertagnolli MM, Eagle CJ, Zauber AG, Redston M, Solomon SD, Kim K, Tang J, Rosenstein RB, Wittes J, Corle D, Hess TM, Woloj GM, Boisserie F, Anderson WF, Viner JL, Bagheri D, Burn J, Chung DC, Dewar T, Foley TR, Hoffman N, Macrae F, Pruitt RE, Saltzman JR, Salzberg B, Sylwestrowicz T, Gordon GB and Hawk ET: APC Study Investigators. Celecoxib for the prevention of sporadic colorectal adenomas. N Engl J Med 355: 873-884, 2006

26. Velayos FS, Terdiman JP and Walsh JM: Effect of 5-aminosalicylate use on colorectal cancer and dysplasia risk: a systematic review and metaanalysis of observational studies. Am J Gastroenterol 100: 1345-1353, 2005.

27. Yoshimura A: Signal transduction of inflammatory cytokines and tumor development. Cancer Sci 97: 439-447, 2006.

28. Greten FR, Eckmann L, Greten TF, Park JM, Li ZW, Egan LJ, Kagnoff MF and Karin M: IKKbeta links inflammation and tumorigenesis in a mouse model of colitis-associated cancer. Cell 118: 285-296, 2004

29. Pikarsky E, Porat RM, Stein I, Abramovitch R, Amit S, Kasem S, Gutkovich-Pyest E, Urieli-Shoval S, Galun E and Ben-Neriah Y: NF-kappaB functions as a tumour promoter in inflammationassociated cancer. Nature 431: 461-466, 2004.

30. Hanada T, Kobayashi T, Chinen T, Saeki K, Takaki H, Koga K, Minoda Y, Sanada T, Yoshioka T, Mimata H, Kato S and Yoshimura A: IFNgamma-dependent, spontaneous development of colorectal carcinomas in SOCS1-deficient mice. J Exp Med 203: 1391-1397, 2006. 